\title{
SINTESIS SILIKA MESOPORI SBA-15DARI ABU DAUN JAGUNG (Zea Mays L)
}

\section{SYNTHESIS OF MESOPORY SILICA SBA-15 FROM CORN LEAVES ASH(Zea Mays L)}

\author{
Nasri,R.R Dirgarini Julia N.Subagyono*, Rahmat Gunawan \\ Laboratorium Kimia Fisik dan Anorganik, Jurusan Kimia, FMIPA, UniversitasMulawaran, Jl. Barong Tongkok, \\ Samarinda, Indonesia \\ *Corresponding Author: dirgarini_julia@yahoo.co.id.
}

Submit : 29 Oktober 2017 Accepted : 06 November 2017

\begin{abstract}
The synthesis and characterization of mesoporous silica Santa Barbara Acid-15 (SBA-15) from the ash of corn have been done. SBA-15 was synthesised using the surfactant template method. SBA-15 from corn leaves ash has a surface area of $592 \mathrm{~m} 2$ / gram, pore volume of $0.99 \mathrm{~cm} 3$ / gram and pore diameter of $3.95 \mathrm{~nm}$ with pore size ranging from $4.9 \mathrm{~nm}-7.1 \mathrm{~nm}$. The SAXS pattern of the bio-SBA-15 showed three typical peaks of SBA-15 with miller indices [100],[110] and [200]. In the FTIR spectrum of SBA-15, peaks from $\mathrm{Si}-\mathrm{O}-\mathrm{Si}, \mathrm{Si}-\mathrm{OH}$ and $\mathrm{H}-\mathrm{O}-\mathrm{H}$ from water were observed.
\end{abstract}

Keywords : Corn leaves ash, mesoporous silica, SBA-15

\section{PENDAHULUAN}

Limbah sering diartikan buangan yang dihasilkan dari suatu proses produksi baik industri maupun domestik (rumah tangga). Proses penghancuran limbah secara alami berlangsung lambat, sehingga limbah tidak saja mengganggu lingkungan sekitarnya tetapi juga mengganggu kesehatan manusia. Sebagai contoh pada perkebunan jagung, akan selalu kita lihat tumpukan daun jagung sebagai limbah perkebunan tersebut. Saat ini pemanfaatan daun jagung masih sangat sedikit, kebanyakan daun jagung hanya dijadikan sebagai pakan atau makanan sapi, sehingga tanaman jagung tetap menjadi bahan limbah yang mengganggu lingkungan [1].

Santa Barbara Acid-15(SBA-15) adalah silika mesopori yang memilikiluas permukaan yang besar, biokompatibilitas tinggi dan kestabilan termal dan hidrotermal tinggi yang memungkinkan untuk digunakan dalam proses katalisis dan adsorpsi [2]. Sintesis SBA-15 biasanya menggunakan tetraetilortositsilikat (TEOS) sebagai sumber silika [3].

TEOS merupakan sumber silika padasintesis SBA-15, akan tetapi TEOS memiliki kelemahan dari aspek kimianya dimana dapat merusak kulit jika terkena dan uapnya dapat mengakibatkan kebutaan [4]. Selain itu, dari segi ekonomi, harga TEOS relatif mahal sehingga jika SBA-15 diproduksi dalam skala besar denganbahandasar TEOS, proses produksitidak bernilaiekonomis. Oleh karena itu perlu dilakukan penelitian lebih lanjut untuk menggantikan peran TEOS dalam pembuatan SBA-15.

Daun jagung mempunyai proporsi sebanyak 20\% dari total limbah tanaman jagung. Daun jagung berbentuk memanjang dan muncul pada setiap buku batang. Jumlah daun terdiri dari 8-18 helaian, tergantung varietasnya. Panjang daun bervariasi yaitu antara $30-50 \mathrm{~cm}$ dengan lebar mencapai $15 \mathrm{~cm}$ [1].Kandungan silika pada daun jagung 64,62 \% dengan kadar abu 12,15\% [5]. Tingginya kandungan $\mathrm{SiO}_{2}$ menjadikan daun jagung berpotensi sebagai bahan baku pembuatan material silikamesopori. Pada penelitian inidilakukansintesis $\quad$ SBA-15 dariabudaunjagung(Zea mays L)sebagaisumbersilikaalternatif. Karakter fisik dan kimia dari material tersebut dianalisisdenganmenggunakanSmall Angle X-Ray Difraction(SAXS) dan $\mathrm{N}_{2}$ adsorption/desorption analyserdan fourier transform infra red (FTIR)spectrophotometer.

\section{METODOLOGI PENELITIAN}

\section{Preparasi Sampel Daun Jagung (Zea Mays L)}

Pada tahap pertama daun jagung dicuci untuk menghilangkan pengotor dan kemudian dikeringkan. Tahap selanjutnya daun jagung dipotong kecil-kecil lalu direndam dengan $\mathrm{HCl} 1$ 
M selama 1 jam dan dibilas dengan aquades hingga $\mathrm{pH}$ netral kemudian dikeringanginkan di bawahsinar matahari lalu diblender. Tahap terakhir sampel biomasa kemudian dimasukan ke dalam furnace dan dipanaskan pada suhu $600{ }^{\circ} \mathrm{C}$ selama 7 jam. Abu yang diperoleh selanjutnya dikarakterisasi menggunakan X-ray Flourescense (XRF).

\section{Ekstraksi Silika Abu Daun Jagung (Zea mays} L)

Abu daunjagung yang diperoleh dilarutkan dalam $\mathrm{NaOH} 1 \mathrm{M}$ dan diaduk selama 7,5 jam pada suhu $75{ }^{\circ} \mathrm{C}$. Campuran ini kemudian disaring untuk memisahkan larutan natrium silikat $\left(\mathrm{Na}_{2} \mathrm{SiO}_{3}\right)$ dengan residu abu. Larutan $\mathrm{Na}_{2} \mathrm{SiO}_{3}$ disimpan sebagai bahan baku pembuatan silika mesopori SBA-15.

\section{Sintesis SBA-15 dari Abu Daun Jagung (Zea mays $\mathbf{L}$ )}

6,58 g Pluronic 123 dilarutkan dalam 250 $\mathrm{mL} \mathrm{HCl} 2 \mathrm{M}$ dengan pengadukan pada suhu 37$40{ }^{\circ} \mathrm{C}$. Larutan $\mathrm{Na}_{2} \mathrm{SiO}_{3}$ hasil ekstraksi dari abudaunjagung ditambahkan ke dalam campuran lalu pengadukan dilanjutkan pada suhu $37-40{ }^{\circ} \mathrm{C}$ selama 20 jam. Setelah 20 jam, campuran dipanaskan pada suhu $100^{\circ} \mathrm{C}$ selama 24 jam pada kondisi statis, proses ini disebut sebagai proses aging. Setelah proses aging, campuran didinginkan pada temperatur kamar, dicuci dengan akuades dan disaring untuk mengisolasi produk yang berupa padatan putih. Sampel kemudian dikeringkan lalu dikalsinasi pada suhu $500 \quad{ }^{\circ} \mathrm{C}$ selama 8 jam.Material SBA-15 selanjutnyadikarakterisasi dengan menggunakan SAXS, $\mathrm{N}_{2}$ adsorption/desorption analysis dan FTIR.

\section{HASIL DAN PEMBAHASAN Preparasi Sampel Daun Jagung}

Preparasisampeldaunjagung dilakukan untuk mendapatkan abu dengan kadar $\mathrm{SiO}_{2}$ yang tinggi, dimana dilakukan proses perendaman menggunakan $\mathrm{HCl}$ sebelum proses pengabuan. Komposisi oksida logam abu daun jagung dapat dilihat dari hasil analisis XRF pada tabel 1.

Tabel 1. Komposisi Oksida logam Abu Daun Jagung

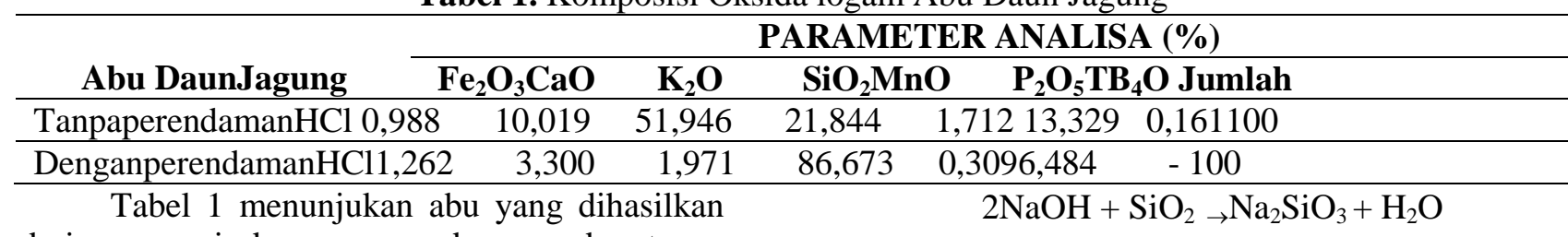

dari preparasi dengan perendaman dan tanpa perendaman $\mathrm{HCl}$. Dari tabel tersebut,dapat dilihat bahwaperendaman dengan $\mathrm{HCl}$ menghasilkan kadar silika yang lebih tinggi dibandingkan tanpa perendaman $\mathrm{HCl}$.Perendamandengan $\mathrm{HCl} 1 \mathrm{M}$ dapat

menurunkankadaroksidalogampadaabudaunjagun gsepertiCaO, $\mathrm{K}_{2} \mathrm{O}$ dan $\mathrm{MnO}$ dibandingkan dengan preparasisampel yang tidak menggunakan perendaman dengan $\mathrm{HCl} 1 \mathrm{M}[6]$.

Hasil ekstraksi silika dari abu daun jagung yakni larutan $\mathrm{Na}_{2} \mathrm{SiO}_{3}$ yang berwarna kuning kecoklatan sebanyak120 mL. Larutan $\mathrm{Na}_{2} \mathrm{SiO}_{3}$ digunakan sebagai bahan baku untuk pembuatan Silika Mesopori SBA-15. Dalam proses ekstraksi terjadi reaksi antara $\mathrm{NaOH}$ dan $\mathrm{SiO}_{2}$ sebagai berikut.
Gambar 1.ReaksiNaOH dengan $\mathrm{SiO}_{2}$ [7]

Dalam sintesis SBA-15 digunakan modifikasi metode surfactant template $[8,9,10]$. Padaproses sintesis SBA-15 diperoleh padatan halus putih.

\section{Karakterisasi material SBA-15}

Analisis SAXS bertujuan untukmengetahui pola difraksi material SBA-15 pada sudut $0-5^{\circ}$ 20. Pada analisis ini didapatkan 3 puncak khas poladifraksi material SBA-15 pada sudut $0-5^{\circ}$ 20. Puncak pertama yang memiliki intensitas tinggi muncul pada sudut $0,93^{\circ} 2 \theta$ dan dua puncak yang memiliki intensitas rendah muncul pada sudut $1,69^{\circ}$ dan $1,85^{\circ} 2 \theta$ (Tabel 2). Difraktogram SBA-15 abu daun jagung dapat dilihat pada Gambar 3. 


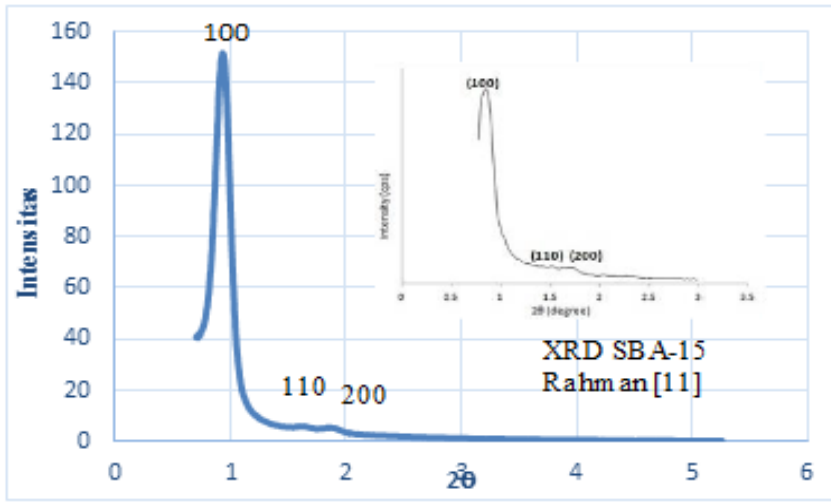

Gambar 1. Difraktogram SBA-15 Abu Daun Jagung

Pada difraktogram SBA-15 abu daun jagung, tiga puncak yang terdeteksi adalah puncak yang terindeks sebagai puncak [100], [110] dan [200] (Tabel 2)

Tabel 2. Perbandingan difraktogram SBA-15 TEOS dan SBA-15 Abu Daun Jagung

\begin{tabular}{|c|c|c|}
\hline \multirow{2}{*}{$\begin{array}{c}\text { PuncakIndeks } \\
\text { Miler }\end{array}$} & \multicolumn{2}{|c|}{${ }^{\circ} 2 \theta$} \\
\hline & $\begin{array}{l}\text { SBA-15 TEOS } \\
\text { DaunJagung }\end{array}$ & SBA-15 Abu \\
\hline 1100 & 0,94 & \\
\hline 110 & 1,69 & 1,61 \\
\hline 3200 & 1,86 & \\
\hline
\end{tabular}

Tabel 2 menunjukan pola SAXS SBA-15 abu daun jagung memiliki kemiripan dengan pola SAXS material SBA-15 yang disintesisolehRahman [10].Munculnya 3 puncak [100], [110] dan [200] dapat mengindikasikan simetri heksagonal dengan space group p6mm yang merupakan ciri SBA-15. Selain itu, munculnya 3 puncakpadarentang $0^{\circ}-<2^{\circ}$ menunjukan bahwa material mesopori bersifat amorf.

Analisis $\mathrm{N}_{2}$ adsorpsi/desorpsi digunakan untuk menentukan volume pori, distribusi pori, dan luas permukaan suatu padatan. Perbandingan SBA-15 abu daun jagung dan SBA-15 TEOS dapat dilihat pada Tabel 3.

Tabel 3. Perbandingan luas permukaan, diameter pori dan volume pori SBA-15 abu daun jagung dengan SBA-15 TEOS.

\begin{tabular}{cccc}
\hline SilikaMesopori & $\begin{array}{c}\text { Luaspermukaan } \\
\left(\mathbf{m}^{\mathbf{2}} / \mathbf{g}\right)\end{array}$ & $\begin{array}{c}\text { Diameter Pori } \\
(\mathbf{n m})\end{array}$ & $\begin{array}{c}\text { Volume Pori } \\
\left(\mathbf{c m}^{3} / \mathbf{g}\right)\end{array}$ \\
\hline SBA-15Abu daunJagung & 594 & 3,95 & 0,99 \\
SBA-15 TEOS & 509 & 2,72 & 0,50 \\
& {$[11]$} & {$[12]$} & {$[11]$} \\
\hline
\end{tabular}

Tabel 3 menunjukan luas permukaan sampel adalah $594 \mathrm{~m}^{2} / \mathrm{gram}$, volume pori 0,99 $\mathrm{cm}^{3} /$ gram yang mendekati parameter SBA-15 dari TEOS Rahman[11]dan diameter pori sampel 3,95 nm yang lebih besar dari diameter SBA-15 dari penelitian Ulfa [12]. Hasil yang didapatkan ini menunjukanbahwa material yang dihasilkanmemiliki karakteristik material mesopori SBA-15.

Hasil uji $\mathrm{N}_{2}$ adsorpsi/desorpsidariSBA-15 abu daun jagung dapat dilihat pada gambar 4 .
Padagambar 4, kurva isoterm menunjukan volume $\mathrm{N}_{2}$ yang diadsorpsi sama dengan volume yang didesorpsi sehingga isoterm adsorpsi SBA15 abu daun Jagung termasuk dalam isoterm tipe 4 yang memiliki loop histerisis yang lebar pada $\mathrm{P} / \mathrm{P}_{\mathrm{o}} \quad 0,4-0,9$ yang menandai terbentuknya multilayer. Menurut Subagyono [10], loop histerisis yang lebar termasuk dalam isoterm tipe 4 yang merupakan isotherm material mesopori. 


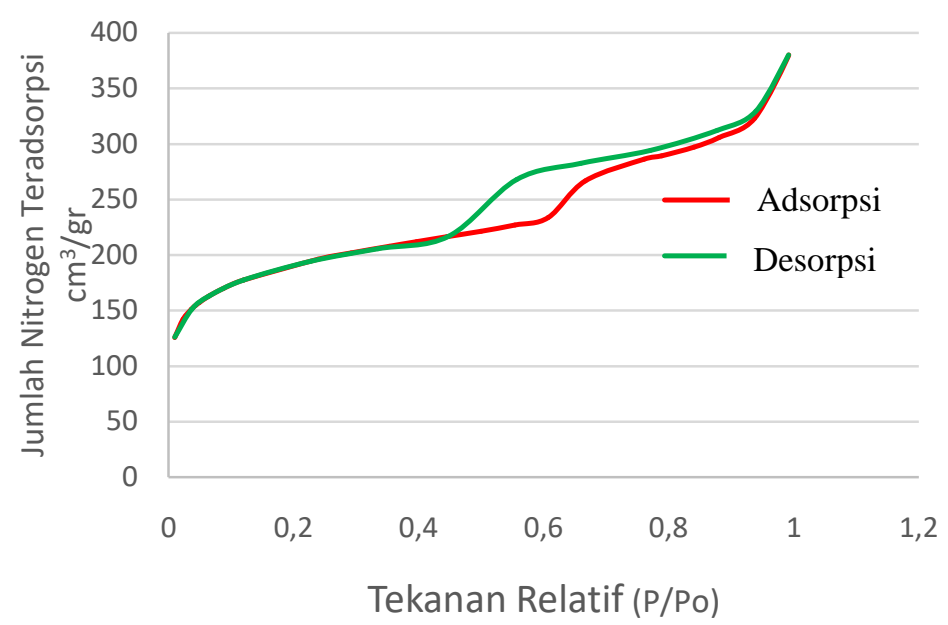

Gambar 4. IsotermAdsorpsi/Desorpsi $\mathrm{N}_{2}$ SBA-15 Abu Daun Jagung

Dari Tabel 3, didapatkan distribusi pori yang ditunjukan pada Gambar 5.

Gambar 5 menunjukan bahwa pori-pori pada material SBA-15 yang disintesis tersebut relatifseragam atau homogen. Ukuran pori dari
SBA-15 abu daun jagung berkisar antara $4,9 \mathrm{~nm}$ $-7,1 \mathrm{~nm}$.

Analisa FTIR digunakan untuk mengetahui gugus fungsi yang terdapat pada material SBA-15. Hasil analisis dapat dilihat pada Gambar 6.

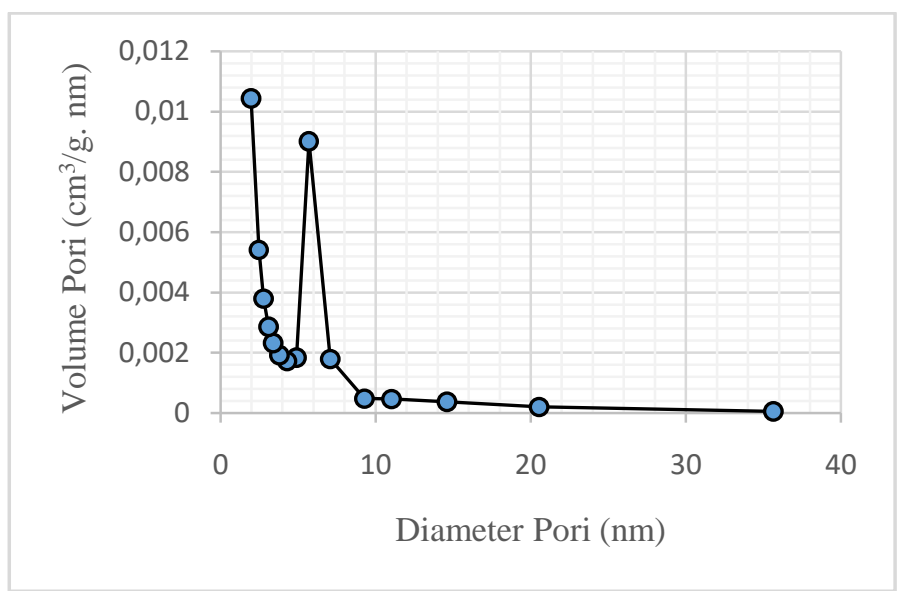

Gambar 5. Distribusi Pori pada SBA-15Abu Daun Jagung

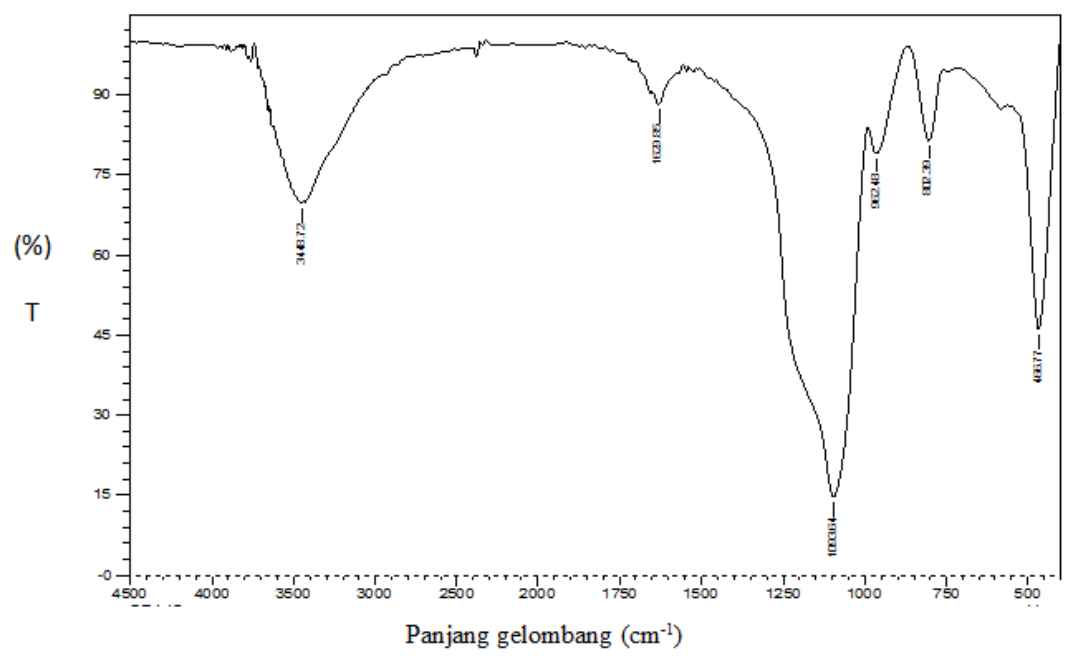


Gambar 6.Spekta FTIR SBA-15 Abu daun Jagung

\begin{abstract}
Berdasarkangambar 6,gugusfungsi Si-O-Si dengan vibrasi ulursimetris $\mathrm{Si}-\mathrm{O}$ diamatipadapanjanggelombang $\quad 467 \quad \mathrm{~cm}^{-}$ ${ }^{1}$ danvibrasiulursimetris O-Si diamatipada panjang gelombang $804 \mathrm{~cm}^{-1}$. Gugus Si-OH munculpadapanjanggelombang $961 \mathrm{~cm}^{-1}$ dan gugus (siloksan)padapanjanggelombang1092 $\mathrm{cm}^{-1}$. Gugus O-H darimolekul air yang terserap SBA15 teridentifikasi pada panjanggelombang 1632 $\mathrm{cm}^{-1}$ danadanyagugus $\mathrm{O}-\mathrm{H}$ dari $\mathrm{Si}-\mathrm{OH}$ (silanol) muncul pada panjanggelombang $3451 \mathrm{~cm}^{-1}$.
\end{abstract}

\section{KESIMPULAN}

Sintesis SBA-15 darilimbahbiomasa, abudaunjagung, telahberhasildilakukan.SBA-15 abu daun jagung memiliki luas permukaan 592 $\mathrm{m}^{2} /$ gram, volume pori $0,99 \mathrm{~cm}^{3} /$ gram dan diameter pori 3,95 nm. Pola SAXS SBA-15 abu daun jagung menunjukan 3 serapan khas dengan indeks miller (100), (110) dan (200). Spektrum FTIR SBA-15 menunjukan adanya gugus fungsi hidroksil (Si-OH) dan siloksan (Si-O-Si).

\section{UCAPAN TERIMAKASIH}

Ucapan terimakasih disampaikankepada Prof. Alan L. Chaffeedari School of Chemistry, Faculty of Science, Monash University,Australia yang telah membantu karakterisasi material SBA15.

\section{DAFTAR PUSTAKA}

[1] Sudjana, A., Rifin, A., dan Sudjadi, M.1991. Jagung. Buletin Teknik No.3 Balitbang Pertanian. Balai Penelitian Tanaman Pangan, 41.

[2] Fedeyko, J. M., Vlachos, D. G., dan Lobo, R. F. 2006. Understanding the differences between microporous and mesoporous synthesis through the phase behavior of silica.Microporous and Mesoporous Materials, 90(1-3 SPEC. ISS.), 102-111.

[3] Cui, H., Zhang, Y., Qiu, Z., Zhao, L., danZhu, Y. 2010. Applied Catalysis B: Environmental Synthesis and characterization of cobalt-substituted SBA15 and its high activity in epoxidation of styrene with molecular oxygen. "Applied Catalysis B, Environmental,"101(1-2), 45-53.

[4] Balgis, R., S. Affandi., H. Setyawan., S. Winardi., A. Purwanto. 2009. A Facile Method for the Production of
High Purity Silica Xerogels from Bagasse Ash. Journal. Adv. Powder Tech. 20 : 468-472.

[5] Zhao, D., Huo, Q., Feng, J., Chemelka, B. F., dan Stucky, G. D. 1998. Nonionic Triblock and Star Diblock Copolymer and Oligomeric Surfactant Syntheses or Highly Ordered, Hydrothermally Stable, Mesoporous Silica Structure, 120, 60246036.

[6] Putra, Angke Rienhar. 2017. sintesis Silika Mesopori SBA-15 Abu Daun Bambu Petung (Dendrocalamus Asper (Schult Backer Ex Heyne) dan Pemanfaatannya sebagai Adsorben Metilen Biru. Samarinda: FMIPA Unmul.

[7] Vogel.1985. Analisis Anorganik Kualitatif Makro dan Semi Mikro. Jakarta : PT. Kalman Media Pustaka.

[8] Margolese, D., J. A. Melero, S. C. Christiansen, B. F. Chmelka, \& G. D. Stucky. 2000. Direct Syntheses of Ordered SBA-15 Mesoporous Silica Containing Sulfonic Acid Groups. Chemistry of Materials 12: 2448-2459.

[9] Ding, T. P., X. Zhou, J., F. Wan, D., Y. Chen, Z., Y. Wang, C., \& Zhang, F.2008. Silicon isotope fractionation in bamboo and its significance to the biogeochemical cycle of silicon, Geochimica et Cosmochimica Acta, No. 72.

[10] Subagyono, Dirgarini J. N, Zhijian Liang, Gregory P. Knowles \& Alan L. Chaffe. 2011. Amine Modified Mesocellular Siliceous Foam (MCF) as a Sorbent for $\mathrm{CO}_{2}$. Chemical Engineering Research and and Design. CRC for Greenhouse Gas Technologies, School of Chemistry, Monash University, Clayton Campus, Wellington Road, Victoria 3800.

[11] Rahman, Nurul Barakah A.B, Hamizah Md. Rasid, Hashazirah Mohammad Hassan, and Mohammad Noor Jalil. 2016. Synthesis and Characterization of Mesoporous Silica.Published by The Malaysian Analytical Sciences Society.

[12] Ulfa, M., Trisunaryanti, W., Falah, and Kartini. 2014. Studies of kinetic on thermal decomposition of mesoporous carbon of gelatin by thermogravimetric technique. Int. J.Innov. Appl. Stud., 7, 849-856. 